\title{
LA CIENCIA MÁS ALLÁ DEL REALISMO Y EL RELATIVISMO
}

Mary Hesse

UNIVERSIDAd DE CAMBridge

En su iluminadora reseña de la filosofía de Foucault, Dreyfus y Rabinow formulan ciertas preguntas sobre la posición de Foucault en las ciencias físico-matemáticas. Una lectura rápida de las obras de Foucault podría seguramente indicar que está conforme en dejar a estas ciencias por la paz. Nos lleva a suponer que Bachelard es el profeta (antes que Kuhn) del cambio epistemológico de la preciencia en ciencia en el caso de la física y la química pero, a diferencia de Kuhn, Bachelard piensa (y Foucault está de acuerdo) que un cambio tal basta para constituir la ciencia sobre una base permanentemente positivista. Canguilhem es el filósofo de la biología que percibe una trama distinta en las características normativas de la biología. Foucault, por otra parte, se concentra a lo largo de su obra en las ciencias humanas vistas como distintas de las ciencias naturales y, por lo menos en primera instancia, toma a estas últimas por dadas. En efecto, hay un momento en que indica que un análisis de las ciencias naturales sería mucho más difícil:

Si a una ciencia como la física teórica o la química orgánica le formulamos el problema de sus relaciones con las estructuras políticas y económicas de la sociedad, ¿no habremos formulado una pregunta demasiado difícil? ¿No habremos elevado el umbral... de explicación a un nivel demasiado alto? $\mathrm{Si}$, por otra parte, tomamos una ciencia como la psiquiatría, ¿̇no serfa mucho más fácil formular la posibilidad de responder a la pregunta de sus relaciones con la sociedad? ${ }^{1}$

El problema aquí es similar al discutido por los partidarios del "programa fuerte" en sociología de la ciencia. Por supuesto que todas las ciencias están sujetas a las coacciones externas de tiempo y espacio, recursos materiales y políticas sociales, pero si se pregunta por el conte-

1 M. Foucault, Power/Knowledge (ed. C. Gordon, Harvester, Sussex, 1980), p. 109. Cfr. en H. L. Dreyfus y P. Rabinow, Michel Foucault: Beyond Structuralism and Hermeneutics (Harvester, Sussex, 1982), p. 115. 
nido interno de una ciencia y de su status como verdad, es mucho más fácil advertir la influencia de estructuras de poder en la construcción interna de las teorias en las ciencias humanas (o en las "seudociencias") que en las naturales. Hoy en día hay muchos estudios sociológicos sobre la génesis de teorías en las ciencias naturales, pero su caracteristica distintiva es que una vez que tales teorías son establecidas y aceptables al consenso de los científicos, parecen "liberarse" de las coacciones y controversias particulares de su origen. ${ }^{2} \mathrm{O}$ para usar otra metáfora, la ciencia positiva se "filtra hacia afuera" de los valores e ideologías y llega a ser, de alguna manera, un componente permanente de conocimiento humano. ${ }^{3}$ La actual sociología de la ciencia de habla inglesa no ha ido más allá de microestudios de orígenes para dirigirse al macroproblema de por qué la ciencia natural aparece como estable y acumulativa a través del tiempo y las culturas.4 Se puede decir, por otra parte, que Foucault tiene una macroteoría (o por lo menos una descripción histórica sumamente extensa) de las ciencias humanas, pero no ha tratado el mismo problema en las ciencias naturales. En este artículo haré un modesto intento por descubrir cuáles son los puntos decisivos.

La pregunta que debemos hacer primero es: ¿Qué es lo que exactamente es "libre" a propósito de la ciencia? Permaneciendo por el momento con Foucault, él parece afirmar una positividad suprahistórica de la ciencia que es esencialmente abierta y por cuya legitimidad no debemos preguntar:

lo que el análisis de la episteme se cuestiona no es su derecho a ser una ciencia, sino el hecho de que exista. Y el punto en que se separa de todas las filosofías del conocimiento... es que relaciona este hecho no a la autoridad de un acto original de dar que establece en un sujeto trascendental el hecho y el derecho, sino que lo relaciona a los procesos de una práctica histórica. ${ }^{5}$

Permanece la ambigüedad acerca de si el "discurso autónomo" que constituye a la ciencia es "libre" por la positividad y progresividad del conocimiento que pretende o porque es la consecuencia de haber acordado proceder de cierta manera en una cultura científica, de acuerdo

2 La terminologia de Foucault sobre la "liberación" del discurso parece venir de Heidegger pero sin relación cercana al significado de Heidegger.

8 Ver mi "Theory and Observation in the Social Sciences" en M. Hesse, Revolutions and Reconstructions in the Philosophy of Science (Harvester, Sussex, 1980), p. 187.

* Observaciones de H. M. Collins sobre el carácter predominantemente microsociológico de los "estudios modernos de ciencia pura contemporánea", en Changing Order (Sage, Londres, 1985), p. 141.

. The Archaeology of Knowledge (trad. A. M. Sheridan Smith, Tavistock, Londres, 1972), p. 192. (La arqueología del saber, Siglo XXI Editores, México, 1970.) 
a un conjunto de reglas adoptadas intencionalmente o no, proporcionando un consenso acerca de los resultados. Tal vez los conceptos superficiales de Foucault acerca de la arqueología y genealogía del discurso no llevan a o no reconocen la validez de tal problema. A pesar de que a menudo se le clasifica entre los filósofos de la ciencia "radicales" antirrealistas, casi cualquiera de las actuales consideraciones analíticas del realismo o antirrealismo podrían ser consistentes con lo que Foucault de hecho afirma.

Consideraré por separado las dos posibilidades sobre la "autonomía", a saber: que es debida al mundo y a cierta "correspondencia" de la ciencia con el mundo; y que es debida al consenso social entre los investigadores. (Más tarde resultará que, después de todo, éstas no pueden separarse por completo.) Aquellos que piensan que la autonomía se debe primeramente al mundo, se llaman generalmente realistas y la filosofía analítica tiene varias versiones del realismo científico. Veamos algunas de sus características relevantes. ${ }^{6}$

Hay un realismo que afirma la existencia de objetos independientemente de todo conocimiento humano o creencias sobre ellos. Este mero realismo del "objeto-en-sí-mismo" no tiene, sin embargo, mucho sentido a menos que se diga algo más acerca de qué clases de objetos existen y cómo los conocemos. Acerca de la ciencia en particular, el realismo de este tipo continúa diciendo que lo que existe es típicamente la clase de cosas que describe la buena ciencia, incluyendo los objetos de sentido común que la ciencia explica, y que la ciencia nos da los medios para conocerlos y mejorar nuestro conocimiento de ellos. Se añade generalmente que esta tesis realista no se ve afectada por el hecho de que el saber cientifico no sea ni infalible ni final, mientras se pueda decir que sabemos algo de él. Aún más, la referencia al "conocimiento" que hace el realismo sostiene que "lo real" no es dependiente de creencias humanas, porque la referencia a la ciencia y a su inseparable conocimiento por sentido común solamente señala cuáles son las clases de objetos reales, independientes, de los cuales se dice que existen. Expresada así, esta forma de realismo científico es probablemente la más fuerte que actualmente se considera sostenible.

Aunque esta idea fuera cierta (y si se aclararan ciertas confusiones que ahora veremos) no bastaría para explicar la persistencia, continuidad y autonomía aparentes de la típica ciencia natural a través de la historia. Contempla en sí misma la existencia de un mundo natural de objetos que parecieran estar esperando que la ciencia los entregue al

6 Estoy endeudada con M. Devitt, Realism and Truth (Blackwell, Oxford, 1984), por un examen reciente y un útil análisis del argumento desde un punto de vista radicalmente realista. 
conocimiento objetivo. Pero obviamente ello no asegura que habrá una institución social de la ciencia que lleve a cabo esta tarea, y aún menos que esta institución permanezca bajo alguna forma reconocible durante un largo período de la historia. Si una tal institución social aparece como resultado de una multiplicidad de factores causales, entonces esta forma de realismo podrá legitimarlo y, por lo tanto, dar cuenta de su persistencia. Pero sólo habrá legitimación si el conocimiento de lo real en este sentido es propuesto también como una meta social o individual. Sin embargo, no trataré en este artículo el problema histórico general de la génesis de la ciencia como institución sino el problema preliminar de la naturaleza de lo que se genera.

Los realistas se inclinan a creer que el saber es una meta válida por sí misma, y que la historia de la ilustración es la historia de la supresión de los obstáculos adventicios y contingentes a esa meta. Como tal, la historia de la ciencia tiene su fascinación pero es a fin de cuentas irrelevante a la comprensión de la naturaleza misma del saber. Quienes rechazan algunas o todas las características de este realismo son los que encuentran una relación más íntima entre el saber científico y la historia, y por lo tanto, surge más intensamente para ellos el problema de la autonomía aparentemente ahistórica. $\mathrm{Y}$ a la luz de la historia y de un examen más detallado de lo que se tiene como saber científico, es muy difícil sostener un tipo de realismo como el descrito. Veamos algunas de las dificultades.

\section{Sentido común y realismo cientifico}

Primero, para salvar al realismo de la vacuidad de las cosas inefables en sí mismas, se hace referencia a objetos de sentido común y a objetos científicos que se dice que conocemos. No es necesario reclamar exclusividad -algunas sociedades y algunos grupos dentro de nuestra sociedad añadirían que también conocemos la existencia de una variedad de dioses, almas, espíritus y tal vez valores morales y estéticos. Es posible ser un realista a propósito de esas cosas. Pero es tal vez indiscutible suponer que los objetos de sentido común (piedras, árboles, personas...) tienen una cierta evidencia y privilegio sobre tales dudosas existencias (en nuestra cultura). En efecto, es difícil concebir una cultura en la que no se dé por supuesta la existencia de objetos de sentido común, como quiera que éstos se describan y en cualquier modelo global en el que se finquen. En cualquier caso, el realismo a propósito de los objetos de sentido común no debe ser punto de discusión al hablar sobre la autonomía de la ciencia, y no quisiera arrojar dudas sobre ello.

Pero el realismo a propósito de los objetos científicos es un asunto 
diferente. Dada la historia de las culturas, no es obvio en lo más mínimo que deba concedérseles privilegio sobre dioses, almas y valores morales. 7 Hacerlo implicaría que la pretensión al conocimiento que surge de la institución de la ciencia adopte algún privilegio y esto incurriría ya en una petición de principio sobre su autonomía y exigiría detallar los medios por los cuales se dice que alcanzamos dicho conocimiento.

Los objetos científicos son cosas como átomos, electrones y campos electromagnéticos que conjuntamente con sus propiedades se postulan como existentes en las teorías científicas. Se dice a veces que son "inobservables", pero esto no es exactamente correcto. Es mejor decir que, si existen, y si la teoría es verdadera, entonces no son observables directamente, sino sólo a través de los efectos que la teoría dice que tienen, y estos efectos sí son observables directamente. Los movimientos brownianos en un microscopio, los trazos en un tubo de rayos catódicos o la fuerza de un campo magnético son observables directamente; pero los objetos de los cuales se dice en las teorías que son sus causas, no lo son.

A veces se afirma que una distinción tal entre lo observable directa e indirectamente es insostenible porque se acepta ahora que "toda observación está impregnada de teoría". Pero esto es un error. Para ver el porqué, debemos ver otra serie de cuestiones sobre la clase de realismo que estamos tratando: éstas se refieren a la relación del lenguaje con lo real.

\section{Ontologia y lenguaje}

Los objetos científicos se postulan en teorías y las teorías son objetos lingüísticos. Esto no es verdadero de los objetos de sentido común, los cuales se presuponen sin pensar en el habla cotidiana; sólo se habla acerca de su existencia cuando surgen dudas y contradicciones en la experiencia habitual, por ejemplo, en relación con las ilusiones perceptuales. Pero la postulación de objetos científicos es inseparable de las producciones lingüisticas y esto es cierto independientemente del peso que se le dé a la habilidad no-verbal y a los pasos intuitivos hacia representaciones de la realidad que son parte de la práctica de experimentación y teorización. Para darse cuenta de esto basta con recordar que los objetos científicos no llegan a aceptarse en la comunidad científica hasta haber sido publicados en una forma predominantemente verbal.

7 Lo que Quine parecia creer en un principio, ver From a Logical Point of View (Harvard, U. P. Cambridge; Mass., 1961), p. 45. (Desde un punto de vista lógico, Ariel, Barcelona, 1962.) Pero en Ontological Relativity and Other Essays (Columbia U. P., New York, 1969), pp. 25 y 138, adoptó un punto de vista científico. (La relatividad ontológica y otros ensayos, Tecnos, Madrid, 1974.) 
Supongamos que nuestro realista tiene razón, y que haya objetos que no son observables directamente ni esperan ser descubiertos y descritos como los objetos de sentido común. Un argumento para hacer esta suposición es seguramente la dificultad de trazar una línea definida entre los objetos observables directa e indirectamente. Pensemos en las lunas de Júpiter. Ahora las aceptamos casi como objetos de sentido común que esperaban ser descubiertos y descritos. Su descubrimiento es hoy en día una parte de conocimiento positivo muy poco probable de ser desmentido por un aumento de datos futuro o una revolución en la teoría. Pero alguna vez fueron vistas como altamente teóricas y no observables de manera directa. Solamente eran visibles a través del recién construido telescopio y las observaciones telescópicas eran poco fiables y abiertas a una variedad de interpretaciones. Las "lunas" podian haber sido artefactos ópticos o conglomerados accidentales de materia entre el lente y el planeta. Hoy en día se aceptan como objetos de sentido común por muchas razones que implican la interpretación de sus relaciones con otros objetos de sentido común y sus comportamientos. Persisten en el tiempo y pueden volverse a identificar. Se mueven regularmente alrededor de Júpiter de acuerdo a las mismas leyes que describen el movimiento de nuestra Luna. La evidencia espectroscópica los revela como compuestos por clases conocidas de materia. Puede enseñarse a jóvenes astrónomos a reconocerlas así como a una más temprana edad se les enseñó a reconocer la Abadía de Westminster o la Estatua de la Libertad, con la ayuda tanto de la observación como de la descripción verbal, pero sin mucho discurso teórico. Pero cuando las lunas de Júpiter eran sujetos de controversia teórica, el discurso teórico era necesario para explicar las inferencias que justificaban la referencia a ciertos objetos como lunas relacionadas al planeta Júpiter cuyos términos estaban y aún están todos impregnados de teoría.

Esto muestra que la carga teórica de los términos que se refieren a objetos observables más o menos directamente no implica que no haya objetos observables de manera directa ni que no puedan describirse mediante enunciados que se acepten como verdades de sentido común. Lo mismo puede decirse de cualquier otro objeto cientifico postulado en teorías. Veamos dos ejemplos de ello: "flogisto" y "electrones".

El flogisto fue postulado en varias teorias del siglo xvrn sobre reacciones químicas, como un fluido gaseoso observable indirectamente. Era inflamable; aparentemente tenía peso negativo o ninguno; producía metales puros a partir del óxido; se desprendía al vaciar ácido sulfúrico al zinc; y se observaba por medio de muchos otros efectos. Ahora decimos que "el flogisto no existe", pero esta afirmación es muy engañosa a menos que se le detalle cuidadosamente. Supongamos que Joseph 
Priestley hubiera restringido su teoría del flogisto a la propiedad de inflamabilidad y a lo que se desprendía cuando se vaciaba ácido sulfúrico al zinc. Nosotros decimos que el gas de que se trata en estos casos es hidrógeno y sabemos mucho más acerca del hidrógeno de lo que Priestley sabia. Pero no hay duda de que en esos experimentos Priestley reconoció y se refirió al "hidrógeno", sólo que le llamó "flogisto". Y porque de hecho tenía una teoría más general en la que aplicaba el término "flogisto" a otras reacciones, se equivocó al identificar la "misma sustancia" en todos esos casos. En otras palabras, su teoría era falsa porque no es, como él pensaba, la misma sustancia la implicada en la oxidación y la respiración, la que es un componente de la atmósfera, etc. No obstante, Priestley sabía muchas verdades acerca del "hidrógeno", y éstas son las verdades que, como en el caso de las lunas de Júpiter, permanecen como parte de nuestro conocimiento positivo de los objetos de sentido común.

Ahora veamos "electrones". Sabemos bastànte acerca de unos pequeños objetos que tienen una cierta carga y masa observables, de los cuales hay clases (aunque no individuos) que podemos identificar, reidentificar y distinguir de otras micropartículas en una gran variedad de experimentos de la física. "Los electrones existen." Pero obviamente sus descripciones están altamente cargadas de teoría, más sutilmente que en el caso del flogisto sólo porque la física es ahora mucho más compleja. ¿Es en principio su status ontológico diferente del del flogisto? No necesariamente. Todo lo que "sabemos sobre los electrones" ha llegado a ser parte de la ciencia positiva así como las lunas de Júpiter y el comportamiento elemental del hidrógeno. Pero las teorías fundamentales de la microfísica son polémicas $y$, actualmente, muy volátiles. Nada puede desechar la posibilidad de una "revolución" en la teoría física que reinterprete muchas identificaciones y leyes acerca de los electrones, de manera similar a lo que sucedió con el flogisto. Dichas revoluciones tienen dos aspectos. En primer lugar, dejan como están muchas verdades locales y particulares en que bien podemos decir que nos referimos a "electrones" aunque en una nueva teorfa los electrones no tengan otras o tal vez más profundas características que las que ahora postulamos de ellos. El hidrógeno arde, con cualquier nombre que le llamemos; los electrones activan tubos de rayos catódicos y contadores Geiger, con cualquier nombre que les llamemos. Pero, en segundo lugar, la nueva teoría podría mostrar que "los electrones no existen" en el caso de que nuestra teoría actual sobre lo que son y cómo se comportan llegara a ser falsa en el detalle y en lo general. De la misma manera en que "no existe el flogisto" porque la teoría de Priestley es falsa en el detalle y 
en lo general. Es decir, falsa de las verdades que han ahora penetrado en el realismo de sentido común.

\section{Particularidad y generalidad}

Este argumento basta para justificar una distinción entre el realismo de sentido común y el realismo científico, aunque el límite entre lo que se considera como objetos aceptados de sentido común y objetos científicos teóricamente dudosos cambie con la historia y el conocimiento. Ha cambiado en un sentido en la historia reciente de la ciencia: ha reclasificado cada vez más objetos cientificos como objetos de sentido común, pero no a la inversa, aparentemente. Tómese nota de que 'sentido común' no se aplica aquí solamente para significar lo que nosotros llamamos sentido común, sino que se ha especificado como aquella clase de objetos (palos y piedras) que se reconocen en la práctica cotidiana de todas las culturas. Pero todo esto deja varios cabos sueltos que son importantes. El primero se refiere al problema de particularidad y generalidad. Nada de lo que hasta ahora se ha dicho acerca de los objetos de sentido común implica que no sepamos más que cosas locales y particulares sobre ellos. Por supuesto que emitimos generalidades y predicciones de ellos: decimos que los palos arden con el fuego y las piedras no, que Júpiter ejerce una fuerza gravitacional sobre sus lunas y que éstas se mueven en órbitas predecibles, que el agua consiste en átomos de hidrógeno y oxigeno. Pero el sentido común es suficientemente sabio para dejar que el significado de dichas afirmaciones sea vago cuando se extrapola a condiciones imaginarias y por mucho tiempo arrastradas, en las que no está justificado suponer que persistan las regularidades locales. ¿Qué significa "arder" bajo la condición de explosión nuclear? ¿Qué puede sucederle a las lunas de Júpiter en la evolución futura del Sol? ¿Qué se entiende por 'átomos' en los primeros microsegundos después del "big bang"? No tenemos teorías completas y satisfactorias de estas cuestiones, y la semántica precisa y las leyes exactas pertenecen sólo a teorías específicas. Hasta ahora, nuestras teorias especificas no son totalmente acertadas, no podemos saber, en el detalle y en lo general, que se apliquen al mundo real, y es dudoso que podamos llegar a saberlo por más "progreso" teórico que se dé en el futuro.

En otra parte he dado argumentos ${ }^{8}$ para mostrar que el éxito local y particular de la ciencia no requiere que haya leyes y teorías generales verdaderas, o por lo menos, no requiere que las conozcamos. Siempre estamos en situaciones locales y particulares por más lejos, en el pasado

8 "Texts without Types and Lumps without Laws" próximo a aparecer en New' Literary History. 
o en el futuro o en la micro o macroescala, que pretendan penetrar nuestras teorías. Más aún, la aplicación de términos generales que hacemos tanto a los objetos de sentido común como a los objetos científicos está siempre sujeta a la ambigüedad de significado cuando se extrapola a condiciones lejanas. Estamos atrapados en algún lenguaje natural cuando hablamos del mundo real y puesto que nunca sabemos si nuestras teorías son estrictamente verdaderas, ni siquiera sabemos expresar las propiedades de objetos que estén bajo condiciones altamente extrapoladas. EI significado local funciona sin captar necesariamente esencias, y sin esencias no podemos expresar leyes estrictamente generales. Esta es la idea que expresa Dummett cuando describe "la cuestión que es el fundamento de varias disputas referentes al realismo" en términos de si "podemos encontrar una concepción de lo que significa que un enunciado sea verdadero, o sea falso, aunque en principio seamos incapaces de reconocerlo como tal", o si "ésta es una ilusión causada por una transferencia ilícita del caso de formas más primitivas de enunciados para cuya comprensión no se requieren tales nociones trascendentales de verdad y falsedad". ${ }^{\circ}$ Desafortunadamente como señala Devitt, ${ }^{10}$ Dummett echa a perder esta idea al requerir de una teoría de verdad que sea proposicional y esto hace que sea inútilmente difícil para él desarrollar una teoría para "formas más primitivas de enunciados" que van más allá de la verificabilidad directa para, por ejemplo, ocuparse de enunciados acerca de ciertos objetos observables indirectamente.

\section{Convergencia y progreso}

Al llegar a este punto, se podría objetar que puesto que es cierto que la ciencia ha dado muestra de tanto progreso en la acumulación de verdades particulares y regularidades locales, seguramente podremos contemplar una extensión indefinida de este proceso hasta el punto en que efectivamente tengamos una teoría general e idealmente verdadera. Es otro problema, por supuesto, el de si la institución de la ciencia sobrevivirá tanto tiempo, pero aun la posibilidad de un resultado tan perfecto podría proporcionar explicación y motivación social para la defensa de la ciencia, a casi cualquier costo.

¿Puede concebirse una teoría tan ideal? La respuesta rápida sería señalar que hay una distancia infinita entre el infinito y aun la más grande acumulación concebible de verdades particulares. $Y$ el punto de vista realista de la ciencia habitualmente exige estricta generalidad en sus

9 M. Dummett, Truth and other Enigmas (Harvard U. P., Cambridge, Mass., 1978), p. XL.

10 M. Devitt, op. cit., p. 205. 
leyes, que deben ser universalmente cuantificadas y pueden ser consideradas aun como afirmaciones de necesidad causal. Una respuesta más cuidadosa tendría que considerar el problema de ver si las teorías reales convergen hacia un limite ideal. El concepto de convergencia ha sido descrito más cuidadosamente por Niiniluoto que por la mayoría de los escritores sobre el realismo. Niiniluoto reconoce que no basta con considerar que una secuencia de teorias converge aparentemente con la verdad en el límite de la ciencia, porque las teorias se expresan en sistemas conceptuales particulares, o sea, lenguajes particulares, y éstos siempre son parciales y pueden ser engañosos. Así es que lo que él tomą en consideración es una secuencia de lenguajes científicos y propone que la limitante teoría científica se comprenda en términos de una secuencia que produzca cada vez más teorías adecuadas localmente. Pero admite que no por ello debemos implicar que "tales sucesiones sean uniforme o monótonamente convergentes". ${ }^{11}$

Esto da, en efecto, sentido a la "idea de la teoría ideal en el límite" pero no nos dice nada sobre la realización de una cosa tal en la práctica. Lo que es cierto es que la secuencia histórica de teorías no muestra ahora ningún proceso uniforme que tienda hacia un límite, sino más bien un número de revoluciones ontológicas no ordenadas de manera lineal. No debe malentenderse este punto. No contradice lo que antes he dicho sobre el progreso, en nuestro conocimiento, de objetos postulados tales como las lunas o los electrones: ese progreso es cuestión de una creciente precisión en el ajuste numérico con el experimento, y acumulación de regularidades bien adaptadas con referencia a las propiedades de los electrones y a sus efectos observables. Pero la ontología de una teoría es algo distinto. Es la respuesta postulada a la pregunta "¿Qué son realmente los electrones?" Y las respuestas a esta pregunta varían radicalmente de teoría a teoría sin mostrar nada que pueda llamarse convergencia. Incluyen una secuencia de modelos imaginativos diferentes de la estructura básica del mundo: los átomos y el vacío, los campos continuos de energía electromagnética, las entidades geométricas en un espacio-tiempo curvo, los complejos de quarks, etc. Excepto por el cese arbitrario de la física teórica, no hay razón para suponer que estas ontologías teóricas lleguen a mostrar estabilidad o convergencia o que en un tiempo dado llegue a haber sólo una ontología indiscutiblemente "mejor".

Parecería que esta ausencia de avance de las ontologías es un argu-

11 I. Niiniluoto, "Scientific Progress", Synthese, núm. 45, 1980, p. 447. Desafortunadamente la medida que hace Niiniluoto de la "apariencia de verdad" presupone que haya por lo menos una ley general verdadera y es, por lo tanto, inaplicable en un mundo en el que no hay leyes generales. 
mento muy recóndito sólo relevante para los más lejanos alcances de la física fundamental y no para la acumulación y convergencia de la ciencia cotidiana. Pero ese juicio depende de lo que buscamos en la ciencia. El progreso local y particular que describimos está relacionado con la resolución de enigmas locales y particulares y específicamente con la posibilidad de predicción y control acertados. Es lo que resulta en el progreso tecnológico, aunque mucho de él no se aplique directamente sino sólo sirva para satisfacer la curiosidad natural, el saber "por el saber". Pero la ideología del saber por el saber es susceptible de tener mayores pretensiones ontológicas y por ello debe hacerse una distinción entre el progreso local y el ontológico. Si hacemos las preguntas generales acerca de la naturaleza que han tenido un perenne interés metafísico, veremos que la mayoría dependen, para su respuesta, de la ontología teórica y no de las ciencias pragmáticas locales y particulares. ¿̨Se rige el universo por azar o por determinación del tipo leyes? ¿Tiene principio o fin en el tiempo? ¿Pueden reducirse todos los fenómenos naturales a la materia en movimiento? ¿Qué es la materia? $\mathrm{Y}$ así sucesivamente. En relación con esas preguntas, la teoría científica está efectivamente coartada en detalle por el requerimiento de la "adecuación empírica", pero su contenido, por otra parte, no goza de un privilegio que conlleve verdad sobre otras clases de metafísica o mitología. En efecto, tiene ella misma muchas de las características y funciones de la mitología en nuestra sociedad.

Es hora de resumir esta parte de la discusión que surgió del intento por aclarar cierto punto del realismo y la noción de "autonomia" que de él se desprende. Acepté la proposición de que hay objetos de sentido común que son independientes de nuestro conocimiento sobre ellos y de los cuales podemos conocer algunas verdades cotidianas. Estos objetos son los que las teorias científicas se proponen explicar, y los objetos científicos se postulan entonces como causas no-directamente-observables de objetos observables y de su comportamiento. En el curso del desarrollo de la ciencia, algunos de ellos llegan a ser aceptados como cognoscibles más o menos directamente, como objetos de sentido común, de manera que se acumulan las verdades sobre ellos constituyendo así el progreso científico. Todo esto es consistente con la suposición de que las descripciones de objetos observables tanto directa como indirectamente son fundamentalmente teóricas, puesto que no podemos escapar al uso de algún lenguaje descriptivo o algún sistema conceptual. Las verdades de sentido común que llegan a aceptarse acerca de los objetos indirectamente observables son, sin embargo, verdades locales y particulares. El avance al adquirirlas no tiene ninguna repercusión en la verdad general y detallada de ninguna teoría científica que pueda concebirse en la práctica. 
Ninguna ciencia que tengamos o que podamos prever muestra convergencia alguna hacia una ontologia idealmente verdadera, sino que sólo muestra una multiplicidad de modelos globales imaginativos radicalmente distintos que o bien han sido descartados en el pasado, o bien permanecen polémicos en el presente. $\mathrm{Y}$ sin embargo son estas ontologías las que dan respuesta a las cuestiones metafísicas que algunos realistas anhelan. Es seguramente el hecho de que la ciencia les ha dado respuesta lo que le ha dado a ella su prestigio metafísico, y le da aun muchas de las características y funciones de una ideología en la sociedad moderna.

La pretensión del realismo ontológico como una meta prácticamente accesible de la ciencia no está necesariamente implicado en el realismo científico que yo originalmente definí. Un realista científico podría estar satisfecho simplemente con la teoría ideal definida de una manera como la de Niiniluoto, independientemente de que la ciencia real sea capaz de alcanzarla o no. La consideración que dicho realista debe hacer es más profunda de lo que habitualmente se admite porque para evitar la vacuidad de la existencia de objetos científicos en-sí-mismos, debe señalar las cosas que la ciencia postula; por lo tanto no puede evitar referirse a algún lenguaje científico u otro; y puesto que la "teoría ideal" sería esencialmente general (a diferencia del discurso de sentido común), tendría él que suponer que el lenguaje científico ideal había captado universalidades naturales, presuponiendo que hay universales naturales. Como he indicado, lo que sabemos de la ciencia no requiere de esta suposición, y es una suposición muy fuerte para la cual no hay ningún argumento convincente.

Un realista científico puede estar satisfecho, por supuesto, con verdades locales y particulares, pero si así es, ha abandonado las pretensiones habituales del realismo de tener algo interesantemente general que decir acerca del mundo natural, y se ha convertido solamente en un realista del éxito local, científico y técnico -el punto de vista que normalmente se llama "instrumentalismo", o que en el mejor de los casos, ve a la ciencia como la solución a problemas locales por el puro deseo de hacerlo. Esta clase de realismo es casi tan débil como el realismo de sentido común, y tan relativamente indiscutible como él.

\section{Consenso y correspondencia}

Hasta ahora hemos hecho una exposición sobre la autonomía de la ciencia basada en su supuesta referencia real al mundo natural y se han indicado las clases de realismo que pueden ser razonablemente sostenidas. He argumentado que el realismo se reduce a algo no muy lejano del instrumentalismo técnico, o a alguna clase de juego-que-resuelve-enigmas 
con la naturaleza. Pero hasta ahora sigue quedando una gran brecha en el argumento y ésta es el status de la "verdad" del cual se ha dicho muchas veces que es una propiedad del progreso local del conocimiento científico. He tratado vagamente el tema de la "adecuación empírica" y he supuesto, con los realistas, que tiene una cierta relación con la "verdad como correspondencia". Pero en varias partes de la exposición el término "verdad" ha sido ambiguo entre correspondencia y consenso. He hablado de "aceptación" de la existencia de objetos de sentido común e indicado que es un asunto relativamente indiscutible y que se da en todas las culturas. He tratado menos claramente la "aceptación" de la existencia de algunos objetos científicos como los postulan las teorías "exitosas". No he tratado aún lo que implican exactamente "aceptación" o "éxito", aparte de la suposición realista de que los objetos están ahí para ser descubiertos y de que la ciencia es el camino para descubrirlos.

Hemos visto que algunas formas intensas de la consideración realista acerca de los objetos científicos son injustificables e innecesarias. Surge entonces la pregunta acerca de qué clase de "verdad" podemos atribuir a los enunciados teóricos que describẹn objetos científicos postulados, además de la comprobación indirecta que estos enunciados adquieren de sus consecuencias observables dentro de todo un sistema de teoría. Dichos enunciados están muy fuertemente indeterminados por datos observables: ¿cómo deben explicarse entonces su "aceptabilidad" y aparente "autonomía"? Los convencionalistas o constructivistas científicos explican la aceptabilidad en términos de una teoría de la verdad fundada en el consenso, y generalmente atribuyen la aparente autonomía de este consenso a la inercia de las reglas y convenciones de la comunidad científica histórica. Los convencionalistas radicales van aún más lejos y explican la aceptabilidad y estabilidad relativa de los objetos "de sentido común" esencialmente de la misma manera. Por ejemplo, Harry Collins ha escrito recientemente, refiriéndose tanto al sentido común como a la ciencia: "No es la regularidad del mundo la que se impone a nuestros sentidos sino la regularidad de nuestras creencias institucionales la que se impone al mundo." ${ }^{12}$ Según Collins, hay una subdeterminación radical, por parte del mundo, de nuestras creencias de sentido común tanto como de nuestras teorías científicas. Bien podríamos ser habitantes de Tlön, a quienes describe Borges como idealistas berkeleyanos practicantes que

conciben el universo como una serie de procesos mentales que no se desarrollan en el espacio sino sucesivamente en el tiempo... La per-

12 H. M. Collins, op. cit., p. 148. 
cepción de una nube de humo en el horizonte y luego del campo que arde y luego del cigarro apagado a medias que produjo el incendio se considera como un ejemplo de asociación de ideas. ${ }^{13}$

El hecho de si seres humanos como nosotros pudieran, en principio, vivir vidas sociales en Tlön, es una cuestión que Borges bien hubiera podido responder. $\mathrm{Y}$ el saber qué tanto se percibe, de hecho, del mundo de sentido común de nuestra cultura a través de todas las culturas humanas, es una pregunta para la antropología. Pero sin exigir la respuesta a estas preguntas debemos hacer notar que el convencionalismo radical acerca de los objetos de sentido común generalmente se basa en la confusión que mencionamos con anterioridad, entre, por una parte, las creencias de que los objetos de sentido común son cosaś existentes y relativamente estables presupuestas en la práctica cotidiana, y por otra parte, el lenguaje conceptual que usamos para categorizarlos y describirlos. El lenguaje puede ser fundamentalmente teórico y cambiante sin impugnar por ello la verdad de las creencias prácticas. Tal vez la "verdad" de las creencias deba verse como un acuerdo o consenso intra e intercultural. Pero si es un consenso basado en el modo en que los seres humanos viven biológica y psicológicamente en su ambiente natural, entonces se vuelve difícil considerar que este consenso que incluye a todos los humanos refleje todo menos una correspondencia con las características naturales del mundo. Estamos ampliamente de acuerdo en nuestras categorías conceptuales dondequiera que tengamos necesidades y propósitos biológicos similares en el mismo mundo.

Habria aquí aguas profundas en las que no quisiera sumergirme en este artículo puesto que lo que nos atañe es la ciencia y no el sentido común. Sin embargo, los convencionalistas tienen razón en señalar una continuidad fundamental entre el sentido común y la ciencia, por lo menos en un aspecto. Me he referido a los fines biológicos cotidianos de los seres humanos, con relación a los cuales las categorías lingüísticas cotidianas son funcionales. Debemos preguntar: ¿Cuáles son los fines de la ciencia en relación con los cuales sus categorías teóricas son funcionales? Esto nos lleva al problema de la "demarcación" de la ciencia, muy manejado por los filósofos positivistas en su intento por distinguir entre las pretensiones al conocimiento "verdaderas" y "falsas", presuponiendo que las pretensiones científicas son las únicas "verdaderas".

El problema de la demarcación fue desacreditado por el doloroso descubrimiento (para los positivistas) de que ningún conjunto de condiciones puede establecerse como necesario y suficiente para que una proposición sea "científica". Dado que es imposible encontrar condiciones

13 J. L. Borges, Labyrinths (Penguin, Londres, 1970), pp. 33-34. 
necesarias y suficientes, desde una lógica externa, para ningún aspecto de la actividad humana, no debe habernos sorprendido este descubrimiento. Pero no debe habernos llevado al abandono total del intento por caracterizar a la "ciencia" y a sus instituciones en términos de un tipo histórico ideal --un método que, después de todo, está muy difundido en las ciencias sociales. Es sorprendente que los sociólogos hayan sido entre toda la gente, los que hayan caido tan fácilmente en la conclusión de los positivistas que afirma que la ausencia de definición lógica precisa implica la futilidad de cualquier intento para categorizar, y los que hayan hecho tan poco por un análisis de tipo ideal. Si la aceptabilidad de la ciencia está relacionada con las costumbres y reglas sociales, entonces debemos hacer una investigación profunda de lo que son estas reglas y costumbres y de cómo se establecieron.

Si fallamos en esa comprensión total, no podremos más que volver a la demarcación descrita por los positivistas, pero sin sus inadecuadas exigencias de rigor lógico y perfección. Lo que llamamos ciencia es un conjunto de instituciones sociales bien fortificadas que data, por lo menos, del siglo xvir y que tiene entre sus fines lo que Francis Bacon describió entonces como "luz" y "fruto": luz para el descubrimiento de las leyes de la naturaleza y fruto resultado de la aplicación de éstas y el subsecuente control de la naturaleza para el beneficio del hombre. Los fines previos respectivamente de la filosofia natural y de la magia se combinaron en uno solo.

Hemos hablado lo suficiente de la estrictamente imposible realización de la meta de descubrimiento de leyes de la naturaleza en el sentido fuertemente realista que adoptó Bacon. Pero el fin del fruto permanece en nosotros y se considera correctamente aún hoy como la extensión del conocimiento de sentido común de los objetos naturales. El método de experimentación y prueba conscientemente iniciado en el siglo xVIr constituyó los "hechos" científicos como la extensión sistemática e institucionalizada de los hechos de sentido común buscados con propósitos que son la extensión de propósitos de sentido común, a saber, el conocimiento para la supervivencia y el control.

Si reconocemos una tal caracterización "de tipo ideal" de las ciencias naturales como ha sido practicada durante cuatro siglos, es entonces muy importante distinguir dos tipos de cosas que dice el convencionalista acerca de la teoria científica. Ambas tesis son correctas en si, pero las conclusiones que de ellas se extraen son distintas. Primero, es correcto ver al tipo histórico ideal de "ciencia" como una convención social en un sentido, no una elegida de manera enteramente intencional pero sin embargo una que pudiera ser intencionalmente abandonada por negligencia o decisión social como hemos visto suceder en regímenes totali- 
tarios y bajo condiciones de decadencia económica. ${ }^{14}$ Aún más, los convencionalistas tienen razón en negarle "racionalidad" exclusiva a este tipo ideal particular. Las sociedades que carecen de ella muestran otras reglas y convenciones de creencias que satisfacen sus requerimientos cognoscitivos, aunque éstos no incluyan un control técnico adecuado y sistemático de la naturaleza. Aquí hay una importante distinción entre aquellos que, como Habermas, quieren renovar el "modernismo" de la Ilustración y aquellos que consideran que el racionalismo de la Ilustración es un callejón sin salida de la historia de las ideas. Los primeros verían al tipo ideal científico como parte de una progresión esencial e irreversible de lo humano; los últimos buscarfan una comprensión más amplia de la razón humana.

En segundo lugar, los convencionalistas tienen razón en considerar al contenido conceptual de las teorías como ampliamente condicionado histórica y socialmente. Pero dentro de la ciencia típica ideal, las teorías también tienen restricciones por lo que constituye el tipo ideal, a saber, la experimentación y contrastación natural y la búsqueda de una adecuación empírica. Hemos preguntado por qué la ciencia natural parece estar relativamente libre del cambio cultural. La respuesta parecería ser que el tipo ideal tiene dos fuentes de autonomía y estabilidad. Una es el interés empírico que en cierto sentido constriñe a una sociedad en sus tratos con la naturaleza y que está sistematizado y extendido por la ciencia natural. La otra es la inercia histórica de la distintiva subcultura de la ciencia y sus intereses profesionales y creencias ideológicas. Los sociólogos han documentado muchos ejemplos de la dificultad para lograr la aceptación de nuevas ideas tanto contra la institución profesional como contra las consideraciones metafísicas tradicionales dentro de esa institución. Fourier y Faraday, marginados con respecto a los grupos científicos de poder, son ejemplos de dificultad profesional. Entre los ejemplos de dificultad ideológica contamos a Einstein, quien presenció una demora de sólo ocho o nueve años para la aceptación de su teoría especial de la relatividad, metafísicamente revolucionaria, pero quien luchó toda su vida por novedosas concepciones de la teoría de campo en toda la física. También está el ejemplo de las consecuencias radicales de la teoría del quantum, que apenas ahora empiezan a ser aceptadas después de seis o siete décadas.

Ambas tesis convencionalistas se derivan de la crítica del realismo que esquematicé anteriormente, y ambas son consistentes con la forma mo-

14 No puede imaginarse una meta más "puramente" cientifica que el proyecto de investigación europeo para la fisica de partículas fundamentales en CERN. Ha sido muy discutida en Gran Bretaña la posibilidad de consecuencias tecnológicas de la suscripción nacional a dicho proyecto. 
dificada de realismo que adopté. Pero los convencionalistas arruinan su argumento al mezclar dos tipos de casos: los que implican un rechazo potencial o implícito del tipo ideal, como por ejemplo las seudociencias de todas clases y algunas formas comunes de parapsicología; y los que aceptan el tipo ideal, y por lo tanto están parcialmente constreñidos por el experimento, pero intentan romper con el molde tradicional de teoría, o con el dominio de un grupo particular de poder científico. ${ }^{15}$

\section{Autonomia}

Tanto Foucault como Habermas, cada quien a su manera, se comprometen con la autonomía de las ciencias naturales. Detrás de ellos está la influencia de Max Weber, y detrás de él la de Augusto Comte. La noción comteana de que la ciencia positiva se ha "desprendido" de la religión tradicional y de la metafísica se convierte en la "ruptura epistemológica" de Bachelard, que todavía tiene fuertes asociaciones positivistas aparentemente aceptadas por Foucault. Cuando Foucault define en La arqueología del saber (p. 188 de la edición inglesa) los umbrales de la positividad, epistemologización, cientificidad y formalización a través de los cuales pasan las formaciones discursivas, puede querer hacer de ellas meras descripciones superficiales de lo que es visible en la historia, pero de hecho son etapas de la racionalización histórica de la ciencia física como las que son vistas por una larga tradición de filósofos franceses desde Comte hasta Duhem y Althusser. Puede variar su interpretación con ciencias diferentes, pero la física es su caso paradigma -el mismo caso que tan precipitadamente ve Foucault. El hecho de que su comprensión sea meramente superficial se revela en su comentario sobre la matemática, que afirma como la única práctica discursiva que ha cruzado todos los umbrales a la vez:

La sola posibilidad de su existencia implicaba que aquello que en todas las otras ciencias permanece disperso en toda la historia, debe darse ahora al principio: su positividad original era constituir una práctica discursiva ya formalizada... en el primer gesto del primer matemático se veía la constitución de una idealidad que se ha desplegado por toda la historia. (Traducción modificada por el autor.)

15 Collins tiende a mezclar estos tipos de casos. Cuando habla de física "normal", como la construcción de un laser-TEA o el "descubrimiento" fracasado de ondas gravitacionales, se nota que casi toda su exposición trata no de las relaciones sociales sìno de luchas manipuladoras con los objetos materiales. En estos casos, las reglas sociales se han subordinado ellas mismas a las restricciones de lo empirico; no se han impuesto a él por completo. 
La historiografía reciente de la matemática no estaría de acuerdo con este cuento de Minerva. ${ }^{16}$

Habermas describe el proyecto de la modernidad misma en términos de Weber de la separación de la ciencia, la moralidad y el arte en sistemas profesionalizados con su propia lógica interna. Busca reintegrar algunos aspectos de esta "modernidad" contra toda forma de relativismo, y se resiste a aceptar la aparente consecuencia de la sociología de la ciencia reciente que afirma que la ciencia puede "asumir la función de creación de significado para la práctica comunicativa de la vida cotidiana". Hay para Habermas una "realidad deshumanizada de las ciencias objetivantes, a las que se les ha suprimido todo significado humano". ${ }^{17}$

Pero la disociación de Weber de la sensibilidad no es irreversible y en cualquier caso las ciencias naturales han tenido siempre un sentido pleno de la comprensión humana del mundo y de los humanos. Esto no ha supeditado la ciencia al relativismo más de lo "relativa" que pueda ser cualquier red de tradición histórica e institución en desarrollo. La historia produce tareas definidas y posibilidades definidas de innovación y no una anarquía del "todo vale". Sin embargo, los cismas de la modernidad no están determinados por necesidad histórica, se derivan de un mal entendimiento de la autonomía característica a la ciencia natural. Esta autonomía tiene poco que ver con el "conocimiento" y mucho que ver con una forma altamente especializada de práctica que está ella misma cada vez más supeditada a intereses tecnológicos y politicos y, por lo tanto, en el sentido social, cada vez más "privados de libertad". Foucault estaría de acuerdo en que esto por sí mismo no es un mal, la tecnología y la política están tan implicadas moralmente como cualquier otra actividad humana. Pero las pretensiones injustificadas de la ciencia al conocimiento y a la racionalidad exclusivos son susceptibles de cegarnos frente al significado de sus relaciones de poder, y es por ello que la postmodernidad necesita un análisis y una crítica exhaustivos de la autonomía científica y su lugar en el mapa cognoscitivo.

Traducción de Marcela Cinta

16 Por ejemplo, I. Lakatos, Proofs and Refutations (Cambridge, U. P. 1976); D. Bloor, Wittgenstein: A Social Theory of Knowledge (MacMillan, Londres, 1983) y L. Wittgenstein, Remarks on the Foundations of Mathematics (Blackwell, Oxford, 1964).

17 Habermas Critical Debates (ed. J. B. Thompson y D. Held) (MacMillan, Londres, 1982), pp. 276-277. 